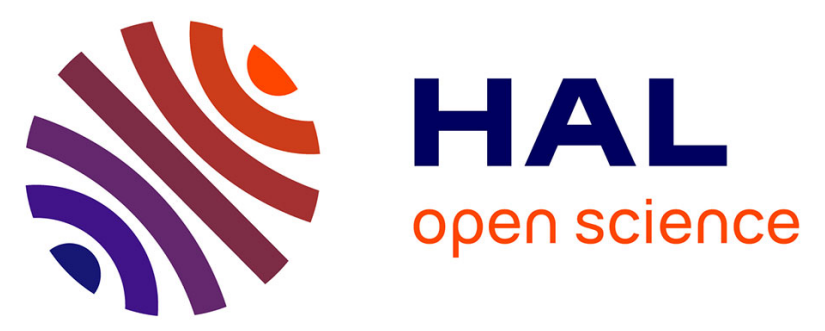

\title{
Osteitis in Systemic Sclerosis: a nationwide case-control retrospective study (SCLEROS Study)
}

Cyril Cossé, Solen Kernéis, Alain Lescoat, Grégory Pugnet, M.-E. Truchetet, Pascal Priollet, Elisabeth Diot, Mickael Martin, François Maurier, Jean François Viallard, et al.

\section{To cite this version:}

Cyril Cossé, Solen Kernéis, Alain Lescoat, Grégory Pugnet, M.-E. Truchetet, et al.. Osteitis in Systemic Sclerosis: a nationwide case-control retrospective study (SCLEROS Study). Arthritis Care and Research, 2022, 74 (05), pp.809-817. 10.1002/acr.24530 . hal-03095565

\section{HAL Id: hal-03095565 \\ https://hal.science/hal-03095565}

Submitted on 12 Jan 2021

HAL is a multi-disciplinary open access archive for the deposit and dissemination of scientific research documents, whether they are published or not. The documents may come from teaching and research institutions in France or abroad, or from public or private research centers.
L'archive ouverte pluridisciplinaire HAL, est destinée au dépôt et à la diffusion de documents scientifiques de niveau recherche, publiés ou non, émanant des établissements d'enseignement et de recherche français ou étrangers, des laboratoires publics ou privés. 
DR. ALAIN LESCOAT (Orcid ID : 0000-0003-2081-8558)

DR. FRANÇOIS MAURIER (Orcid ID : 0000-0002-3222-8566)

DR. BRIGITTE GRANEL (Orcid ID : 0000-0001-7995-8817)

DR. BENJAMIN CHAIGNE (Orcid ID : 0000-0001-5448-7860)

Article type : Original Article

\section{Osteitis in Systemic Sclerosis:}

\section{a nationwide case-control retrospective study (SCLEROS Study)}

Cyril Cosse $^{1}$ phD; Solen Kernéis ${ }^{2} \mathrm{MD}$, phD; Alain Lescoat ${ }^{3} \mathrm{MD}$, phD; Gregory Pugnet ${ }^{4} \mathrm{MD}$, phD; Marie-Elise Truchetet ${ }^{5} \mathrm{MD}$, phD; Pascal Priollet ${ }^{6} \mathrm{MD}$; Elisabeth Diot $^{7} \mathrm{MD}$, phD; Mickael Martin $^{8}$ MD, phD; François Maurier ${ }^{9}$ MD; Jean François Viallard ${ }^{10}$ MD, phD; Christian Agard ${ }^{11}$ MD, phD; Brigitte Granel ${ }^{12}$ MD, phD; Sabine Berthier ${ }^{13}$ MD; Dorothée Fagedet ${ }^{14}$ MD; Bénédicte Watelet ${ }^{15} \mathrm{MD}$; Ségolène Toquet ${ }^{16} \mathrm{MD}$; David Luque Paz ${ }^{17} \mathrm{MD}$, phD; Cloé Giret ${ }^{7} \mathrm{MD}$; Olivier Cerles $^{1}$ phD ; Jérémie Dion ${ }^{1} \mathrm{MD}$; Christelle Nguyen ${ }^{18} \mathrm{MD}$, phD; Loïc Raffray ${ }^{19} \mathrm{MD}$, phD; Julien Bertolino $^{12} \mathrm{MD}$; Wendy Jourde ${ }^{10} \mathrm{MD}$; Claire Le Jeunne ${ }^{1} \mathrm{MD}$, phD; Luc Mouthon ${ }^{1} \mathrm{MD}$, phD \& Benjamin Chaigne ${ }^{1} \mathrm{MD}$, phD

${ }^{1}$ Service de Médecine Interne, Centre de Référence Maladies systémiques auto-immunes rares d'lle de France, Hôpital Cochin, Université Paris Descartes, Assistance Publique-Hôpitaux de Paris (AP-HP), Paris, France.

${ }^{2}$ Antimicrobial Stewardship Team, APHP, Cochin hospital, University of Paris, Paris, France

This article has been accepted for publication and undergone full peer review but has not been through the copyediting, typesetting, pagination and proofreading process, which may lead to differences between this version and the Version of Record. Please cite this article as doi: 10.1002/ACR.24530 
${ }^{3}$ Université Rennes, CHU Rennes, Inserm, EHESP, Irset (Institut de recherche en santé, environnement et travail) - UMR_S 1085, F-35000 Rennes, France; Department of Internal Medicine and Clinical Immunology, Rennes University Hospital, 35203, Rennes, France

${ }^{4}$ Service de Médecine Interne, CHU Toulouse, Toulouse, France ; Centre d'Investigation Clinique 1436, $\mathrm{CHU}$ Toulouse, Toulouse, France

${ }^{5}$ Rheumatology department and national center of reference for rare autoimmune diseases, Bordeaux University Hospital

${ }^{6}$ Service de médecine vasculaire, Hôpital Saint Joseph, Paris, France

${ }^{7}$ Service de médecine Interne, Hôpital Bretonneau, Tours Cedex, France

${ }^{8}$ Service de Médecine Interne, Maladies Infectieuses et Tropicales, CHU de Poitiers, Poitiers, France

${ }^{9}$ Centre de compétence des maladies rares, Hôpitaux privés de Metz, Metz, France

10 Département de Médecine Interne et Maladies Infectieuses, Centre Hospitalier Universitaire Haut Lévêque, Université de Bordeaux, Pessac, France

11 Service de médecine interne, Hôtel-Dieu, CHU Nantes, Hôpital, Université de Nantes

12 Service de Médecine Interne, Hôpital Nord, Aix-Marseille Université, Assistance Publique-Hôpitaux de Marseille (AP-HM), Marseille, France

${ }^{13}$ Service de Médecine Interne et Immunologie Clinique, CHU F MITTERRAND, Dijon, France

${ }^{14}$ Service de Médecine Interne - CHICAS, hôpital de GAP

${ }^{15}$ Service de Médecine Interne, CHU Caen, Caen, France

${ }^{16}$ Pôle médecine, CHU Robert Debré, Reims, France

${ }^{17}$ Service des Maladies Infectieuses et Réanimation Médicale, CHU Rennes, France

18 Service de Rééducation et de Réadaptation de l'Appareil Locomoteur et des Pathologies du Rachis, Hôpitaux Universitaires Paris Centre-Groupe Hospitalier Cochin, Assistance Publique-Hôpitaux de Paris, 75014 Paris, France ; Université de Paris, Faculté de Santé, UFR Médecine Paris Descartes, Sorbonne Paris Cité, 75006 Paris, France; INSERM UMRS 1124, Toxicité Environnementale, Cibles Thérapeutiques, 
Signalisation Cellulaire et Biomarqueurs, UFR Sciences Fondamentales et Biomédicales, Centre Universitaire des Saints-Pères, 75006 Paris, France.

${ }^{19}$ Service Médecine Interne et Dermatologie ; CHU Réunion- Hôpital Félix Guyon, Saint Denis, France

Correspondance: Dr Benjamin Chaigne, Service de Médecine Interne, Centre de Référence Maladies systémiques auto-immunes rares d'lle de France, Hôpital Cochin, Assistance Publique-Hôpitaux de Paris, 75014 Paris, France.

Tel: +33 (0) 158412031 / Fax: +33 (0) 158411450

E-mail: benjamin.chaigne@aphp.fr

Word count of abstract: 337 , of manuscript: 2741

Number of references: 33

Number of Tables: 5

Number of Supplementary Tables: 3

\section{Declaration of interest : None.}

\section{Funding: None}

Key words: systemic sclerosis, osteitis, antibiotics, digital ulcers

CRediT author statement: Cyril Cosse (conceptualization; methodology; formal analysis ; writing original draft); Solen Kernéis ${ }^{2}$ (methodology; formal analysis ; writing original draft); Alain Lescoat ${ }^{3}$ (investigation; writing review and editing); Gregory Pugnet ${ }^{4}$ (investigation; writing review and editing); Marie-Elise Truchetet $^{5}$ (investigation; writing review and editing); Pascal Priollet $^{6}$ (investigation; writing review and editing); Elisabeth $\operatorname{Diot}^{7}$ (investigation; writing review and editing); Mickael 
$\operatorname{Martin}^{8}$ (investigation; writing review and editing); François Maurier ${ }^{9}$ (investigation; writing review and editing); Jean François Viallard ${ }^{10}$ (investigation; writing review and editing); Christian Agard $^{11}$ (investigation; writing review and editing); Brigitte Granel $^{12}$ (investigation; writing review and editing); Sabine Berthier ${ }^{13}$ (investigation; writing review and editing); Dorothée Fagedet ${ }^{14}$ (investigation; writing review and editing); Bénédicte Watelet ${ }^{15}$ (investigation; writing review and editing); Ségolène Toquet ${ }^{16}$ (investigation; writing review and editing) ; David Luque $\mathrm{Paz}^{17}$ (investigation; writing review and editing); Cloé Giret ${ }^{7}$ (investigation; writing review and editing); Olivier Cerles $^{1}$ (visualization; writing review and editing); Jérémie Dion ${ }^{1}$ (investigation; writing review and editing); Christelle Nguyen $^{18}$ (investigation; writing review and editing) ; Loïc Raffray ${ }^{19}$ (investigation; writing review and editing); Julien Bertolino ${ }^{12}$ (investigation; writing review and editing); Wendy Jourde ${ }^{10}$ (investigation; writing review and editing); Claire Le Jeunne ${ }^{1}$ (conceptualization; methodology; formal analysis ; writing original draft); Luc Mouthon ${ }^{1}$ (conceptualization ; methodology; formal analysis ; writing original draft) \& Benjamin Chaigne ${ }^{1}$ (supervision; project administration; conceptualization ; methodology; formal analysis ; writing original draft) 


\section{ABSTRACT}

Objective: Systemic sclerosis (SSc) is an autoimmune (AI) connective tissue disorder characterized by skin fibrosis, vasculopathy and dysimmunity. Data regarding osteitis in SSc are scarce.

Method: We performed a nationwide multicentre retrospective case-control study including patients with SSc according to the 2013 ACR/EULAR classification, with a diagnosis of osteitis. The objectives of the study were to describe, to characterize, and to identify associated factors for osteitis in patients with SSc.

Results: Forty-eight patients were included. Twenty-six patients (54.1\%) had osteitis beneath digital tip ulcers. Physical symptoms included: pain $(36 / 48,75 \%)$, erythema $(35 / 48,73 \%)$, and local warmth $(35 / 48,73 \%)$. Thirty-one $(65 \%)$ patients had C-reactive protein levels $>2 \mathrm{mg} / \mathrm{L}(8$ [2.7 - 44.3] mg/L). On X-ray, CT-scans or MRI, osteitis was characterized by swelling or abscess of soft tissues with acro-osteolysis or lysis in 28 patients (58\%). Microbiological sampling was performed in 45 (94\%) patients. Most pathogens were Staphylococcus aureus (43.8\%); anaerobes and Enterobacteriaceae (29.1\%) and Pseudomonas aeruginosa (10.4\%). Management comprised antibiotics in 37 (77.1\%) patients and/or surgery in 26 (54.2\%). Fluoroquinolones were used in 22 (45.8\%) patients and amoxicillin + beta-lactamase inhibitor in 7 (14.6\%). Six (12.6\%) patients relapsed, $6(12.6 \%)$ patients had osteitis recurrence, $15(32 \%)$ sequelae, and 2 patients had septic shock and died.

Conclusion: This study confirmed digital tip ulcers as an associated factor for osteitis, and revealed a high rate of functional sequelae. Antimicrobial therapy with oral fluoroquinolone or intravenous amoxicillin and beta-lactamase inhibitor are used as first-line antibiotherapy in SSc patients with osteitis. 


\section{SIGNIFICANCE AND INNOVATIONS}

- $54.1 \%$ of osteitis in systemic sclerosis (SSc) patients occurred beneath digital ulcers

- Most frequent pathogens in SSc osteitis were Staphylococcus aureus, anaerobes and Enterobacteriaceae, and Pseudomonas aeruginosa

- $\mathrm{SSc}$ osteitis is associated with $25.2 \%$ of relapse or recurrence, $32 \%$ of sequelae and 2 death due to septic shock

- Antibiotic biotherapy with either oral fluoroquinolone or intravenous amoxicillin and betalactamase inhibitor were mainly used as first-line antibiotherapy in SSc patients with osteitis 


\section{INTRODUCTION}

Systemic sclerosis (SSc) is an autoimmune connective tissue disorder characterized by skin sclerosis due to fibroblast activation and extra-cellular matrix synthesis, vasculopathy including vascular hyperactivity and remodeling and dysimmunity (1-3). Because of microangiopathy, patients with SSc have a compromised vascular supply and present with Raynaud's phenomenon and digital ulcers, which put them at risk of osteitis (4-7).

Osteitis is an infection resulting from the contamination of the bone by one or more pathogens. Such infection results either from direct inoculation or from secondary hematogenous spread. It causes an inflammatory reaction with the secretion of proinflammatory cytokines such as tumor necrosis factor alpha (8). Inflammatory cytokines then stimulate the activation of osteoclasts and osteoblasts, which leads to bone resorption and periosteal reaction, respectively. In case of prolonged osteitis or in patients with diabetic foot infection, ischemic lesions enhance the occurrence of an infection and favor bone necrosis and osteolysis (9). Patients are subsequently at risk of gangrene and amputation.

Gangrene has been reported in SSc and occurs mainly in smoking, anti-Scl70 positive patients with digital ulcers and a history of previous infection, including osteitis (10). Oppositely, osteitis has been less described in SSc. Even though it is a severe infection, which inevitably impacts patients' quality of life and is responsible for a high morbidity, very few studies have focused on its description and management in patients with SSc.

Herein, we report the nationwide SCLEROS study, which aimed at characterizing osteitis in patients with SSc.

\section{PATIENTS AND METHODS}

\section{Study design}

SCLEROS is a retrospective, multicentre, nationwide case-control study performed in France. Between January and June 2019, physicians belonging to the following scientific societies: GFRS 
(Groupe Francophone de Recherche sur la Sclérodermie), SNFMI (Société Nationale Française de Médecine Interne); SPILF (Société de Pathologie Infectieuse de Langue Française) and CRI (Club Rhumatismes et Inflammations) were asked to recall and report all cases with SSc and osteitis managed between 2000 and 2019.

\section{Objectives}

The primary objective of the study was to describe and characterize osteitis in SSc patients. The secondary objective was to identify associated factors for osteitis in patients with SSc.

\section{Study population}

Inclusion criteria were: male or female patients over 18 years old, diagnosis of systemic sclerosis according to the $2013 \mathrm{ACR} / \mathrm{EULAR}$ classification (11), diagnosis of osteitis according to the physician in charge of the patient suspected on the basis of clinical, laboratory, and confirmed by radiological findings or surgical bacteriological sampling, namely, the presence of clinical signs/symptoms (local pain, swelling, erythema around the skin ulcer, warmth, purulent discharge, fever), blood chemistry alterations (C-reactive protein, and/or increased white blood cell count), positive microbiological surgical sample or radiological findings. The latter included the following: soft-tissue swelling, periosteal reaction or elevation, loss of cortex with bone erosion, focal loss of trabecular pattern, new bone formation, bone sequestrum, involucrum, and/or cloacae $(12,13)$. For each case, 4 controls with SSc according to the 2013 ACR/EULAR classification without osteitis were randomly extracted from the SSc database of the national referral centre for $\mathrm{AI}$ and systemic disease $(14,15)$.

\section{Data source}

Data comprised subset classification of SSc (limited or diffuse cutaneous SSc) according to LeRoy and Medsger classification (16); disease duration; clinical profiles (modified Rodnan skin score, digital vasculopathy and other visceral impairment); antibody profile and patients' comorbidities.

Collected data related to osteitis were the following: location, clinical and biological presentation of osteitis, microbiological data and management. Superficial samples were defined as thin-needle aspiration, deep samples were defined as bone biopsies performed during surgery. A new episode of osteitis was defined as another osteitis at a different location within 6 months. 


\section{Statistical analysis}

Quantitative variables were expressed as the mean \pm standard deviation (SD) or (for a nonGaussian distribution) the median [interquartile range] [IQR] and compared with Mann-Whitney test. Qualitative variables were expressed as the number (n) and percentage (\%) and compared with Chi-square test.

Associated factors for osteitis occurrence and osteitis healing were identified according to a twostep logistic regression. First variables with a $\mathrm{p}$ value $<0.15$ in the univariate analysis were included in the multivariate analysis. These variables were considered as independent associated factors if the $p$ value after the multivariate analysis was $\leq 0.05$

Statistical analysis was performed with STATA 15.1 software (StataCorp LLC, Texas, USA). Results are reported according to the STROBE guidelines reporting data of observational studies (17).

\section{Ethics}

The study was approved by the local ethics committee (CER Paris Descartes) n² 2018-93. 


\section{RESULTS}

Forty-eight patients with SSc and osteitis were included in the SCLEROS study. No case was removed from the analysis because of data lacking. Populations' baseline characteristics are showed in table 1. SCLEROS cases comprised typical SSc patients with $77.1 \%$ of Caucasian female (median [interquartile range] age of 58.5 [48.5 - 68.5] years old). Eighty-five per cent had puffy fingers, 79.4\% sclerodactyly, 95.8\% Raynaud's phenomenon and 54.2\% abnormal nailfold capillaries on capillaroscopy. Fifty-two percent of patients had positive anti-centromere autoantibodies and $6.3 \%$ positive anti-RNA polymerase III autoantibodies. Only $25 \%$ patients had been treated with immunosuppressant drugs at the time of osteitis. Five (10.4\%) patients were treated with bosentan ( 3 with digital tip ulcers and 2 without).

When compared to SSc controls $(\mathrm{n}=192)$, SCLEROS cases had higher mRSS (modified Rodnan skin score) $(7[4-18]$ vs 4 [2 - 8], p=0.008). The occurrence of interstitial lung disease was less frequent $(35.4 \%$ vs $53.4 \%, \mathrm{p}=0.03)$. Osteitis occurred mostly in patients with a long disease duration of SSc (110 [30 - 204] vs 44 [17 - 109] months, $p=0.004)$ and predominantly in patients with dSSc (35.4\% vs $20.8 \%, \mathrm{p}=0.03)$.

\section{Description of osteitis episodes}

Osteitis characteristics are showed in table 2.

\section{i/ Clinical presentation}

Osteitis in the SCLEROS population occurred predominantly in distal portions of the limbs (91.7\% patients), mainly hands $(52.1 \%)$. Five (10.4\%) patients had osteitis over the proximal phalangeal joints. Other locations included toes $(n=19)$, elbows $(n=2)$, femur $(n=1)$ and sternum $(\mathrm{n}=1)$. Digital ulcers and calcinosis were reported overlying the osteitis location in $26(54.1 \%)$ and $13(27.1 \%)$ cases, respectively. Physical symptoms included pain (75\%), erythema (72.9\%), and local warmth (72.9\%). In most cases (44/48, $91.7 \%$ ), fever was absent. Purulent discharge was reported in $56.3 \%$ of patients.

The patient with sternum osteitis (a fifty-six years-old male) presented with a 6-month diagnostic of dSSc and positive anti-topoisomerase I antibodies. He had history of calcinosis, interstitial lung disease and gastroesophageal reflux disease. Osteitis was suspected on local pain associated with 
local warmth, functional disability and erythema and confirmed on X-Ray. C reactive protein was $60 \mathrm{mg} / \mathrm{L}$. He was successfully managed with antibiotics, with no sequelae and no recurrence. The patient with femur osteitis (a seventy-two years-old female) presented with a 4-year diagnostic of ISSc and positive anti-centromere antibodies. She had history of calcinosis and gastroesophageal reflux disease. Osteitis was suspected on local pain on the amputation site on her femur associated with local warmth, functional disability, purulent discharge and erythema and confirmed on MRI. $\mathrm{C}$ reactive protein was $66 \mathrm{mg} / \mathrm{L}$. She was successfully managed with antibiotics and surgical joint cleansing, with no sequelae. She presented a new episode of osteitis at the same location 6 months after the first episode and was successfully managed with antibiotics.

When comparing osteitis beneath digital ulcers to other osteitis (i.e. those without underlying digital ulcer), osteitis beneath digital tip ulcers mostly resembled other osteitis (tables 2, 3) but osteitis beneath ulcers were more frequently associated with local swelling and erythema (73.1\%, $\mathrm{p}=0.004 ; 84.6 \%, \mathrm{p}=0.04$ respectively).

\section{ii/ Laboratory investigations}

Thirty-one (64.6\%) patients had an increased C-reactive protein (CRP) with a median [IQR] CRP value of $8[2.7-44.3] \mathrm{mg} / \mathrm{L}(\mathrm{N}<5 \mathrm{mg} / \mathrm{L})$. Hyperleukocytosis $\left(>8000\right.$ leukocytes $\left./ \mathrm{mm}^{3}\right)$ was present in $27.1 \%$ of patients. Other blood count parameters were within the normal range. No difference was reported for biological documentation for osteitis beneath digital tip ulcers when comparing with osteitis without (w/o) digital tip ulcers.

\section{iii/ Imaging manifestations}

In the SCLEROS population, only two (4.2\%) patients did not have any imaging performed. Standard X-ray ( $\mathrm{n}=36$ patients) reported osteolysis or acro-osteolysis in 17 patients; subcutaneous calcifications in 6 patients and thickening of soft tissues in 5 patients. MRI $(\mathrm{n}=17$ patients) reported localized collection in 3 patients, soft tissues swelling in 12 patients, thickening of soft tissues in 10 patients; loss of tissue surrounding in 2 patients and acro-osteolysis in 5 patients. CT-scan ( $n=8$ patients) reported cortical osteolysis with loss of tissue surrounding in 6 patients. Fifteen patients (31.3\%) had either X-ray and MRI or X-ray and CT-scan or MRI and CT-scan. On X-ray, CT-scan or MRI, osteitis were characterized by swelling or abscess of soft tissues with acro-osteolysis or lysis in 28 patients (58.3\%). Additional osteitis' description 
included localized collection and swelling of soft tissues w/o acro-osteolysis that were only reported in $6.3 \%$ of radiological reports.

\section{iv/ Microbiological documentation}

Out of 48 patients, $40(83.3 \%)$ patients had microbiological sampling. Sampling was performed either superficially or deeply. Seventy-seven per cent of superficial samples and $88.9 \%$ of deep samples allowed the identification of at least one pathogen species. Out of 40 patients with samples, 3 had sterile samples (7.5\%) including 2 surgical samples and 1 needle-guided sample. Out of 37 seven samples with identified microorganisms, 18 samples (48.6\%) had more than one identified microorganism. Overall, the most frequent pathogens were Staphylococcus aureus (43.8\%); anaerobes and Enterobacteriaceae (29.1\%) and Pseudomonas aeruginosa (10.4\%). No difference was found in terms of pathogens occurrence considering the presence of digital tip ulcers.

\section{$\mathrm{v} /$ Osteitis management}

Management of osteitis involved several specialists (internists, infectious diseases specialists, orthopaedic surgeons) in 50\% of cases. Management consisted in antibiotics in $77.1 \%$ of patients and/or surgery in $54.2 \%$ of patients (synovectomy $4.2 \%$ or amputation $22.9 \%$ ) (table 3 ).

Main antibiotic regimens are summarized in table 4. Fluoroquinolones were used in $45.8 \%$ of patients, macrolides or lincosamides in $18.8 \%$ and amoxicillin and beta-lactamase inhibitor in 14.6\%. First-line antibiotics were fluoroquinolone, orally, as a bitherapy for 34 [IQR 10 - 50] days or amoxicillin +/- $\beta$-lactamase inhibitor, orally, as a bitherapy for 30 [IQR 12 - 42] days. Secondline antibiotics were fluoroquinolone, orally for 32 [IQR 27 - 42] days or rifampicin, orally, for 42 [IQR 35 - 67] days as a bitherapy. Detailed regimens are presented in the supplementary table 1.

After 5 [IQR 2 - 18] months of median follow-up, osteitis healing was reported in 72.9\% of patients. Relapse was observed in $6(12.6 \%)$ patients (1 relapse per patient), within two months following the diagnosis of the first episode. Six (12.6\%) patients experienced a new episode of osteitis. Noteworthy, such osteitis recurrence location was contralateral to the first episode in 5/6 patients. The time before recurrence was 4 [IQR 2 - 6] months. For 1 patient, the same antibiotic was continued for 3 months (amoxicillin + clavulanic acid). For another, the antibiotic was 
switched to piperacillin / tazobactam then cefazolin for 3 months. For the 4 others, an amputation of the affected limb was required.

Thirty-two percent of patients had functional sequelae after management including those related to amputation. Two patients died of septic shock leading to multiple organ failure secondary to osteitis. When comparing osteitis beneath digital ulcers and other osteitis location, management and prognosis were similar.

\section{vi/ Osteitis management in patients with sterile samples}

Eleven patients were managed without any microbiological documentation. Three patients had sterile samples. The first patient was managed with an oral bitherapy (levofloxacin + clindamycin) for 6 weeks with a clinical healing of osteitis and no recurrence at 2 months. The second patient was managed with an oral monotherapy (cloxacillin), for 20 days then an oral monotherapy (clindamycin) for 6 weeks with a clinical healing of osteitis and no recurrence at 2 months after the beginning of treatment. The third patient was surgically managed. For eight patients, no microbiological sampling was performed. All these patients were treated with antibiotics for 10 days to 6 weeks (penicillin +/- inhibitors in 2 patients; fluoroquinolone for 4 patients and rifampicin for 2 patients). Additional local wound cares with dressing were used until healing. Among the eight patients, two required a surgical management (amputation for both) due to a lack of clinical improvement. Six patients were healed at 6 months and two had functional sequelae because of the amputation.

vii/ Associated factors for osteitis and osteitis' healing

Associated factors for osteitis' occurrence are presented in table 5. Among the tested variables, digital tip ulcers $(\mathrm{RR}(95 \% \mathrm{CI})=4.26(1.43-12.66), \mathrm{p}=0.009)$ and calcinosis $(\mathrm{RR}(95 \% \mathrm{CI})=$ $3.13(1.16-8.47), \mathrm{p}=0.03)$ were found as independent associated factors for osteitis.

Associated factors for osteitis' occurrence on digital tip ulcers are presented in the supplemental table 2. Among all the tested variables, age $(\mathrm{RR}(95 \% \mathrm{CI})=1.06(1.01-1.12), \mathrm{p}=0.03)$ was found as independent associated factor for osteitis on digital tip ulcers.

Among all the tested variables to identify factors with osteitis healing, none was found as an independent associated factor (supplemental table 3). 


\section{DISCUSSION}

This daily life study confirms that the presence of digital ulcers is an associated factor for osteitis in SSc patients. This finding is in accordance with the series of Giuggioli et al., in 2013, which showed that osteoarticular infections such as osteomyelitis were common in patients with SSc and skin ulcers (18). Moreover, digital ulcers predicted the worsening of SSc and were complicated by osteitis in 5 to $23 \%$ of cases $(7,19-22)$. In their 2016 prospective, observational cohort; Allanore et al. sought the clinical features related to the occurrence of gangrene in patients with SSc. The authors found that digital ulcers, as well as smoking status, anti-Scl 70 antibodies, and a history of previous infection (gangrene, osteomyelitis) were associated with increased bone infections (10). The SCLEROS study confirmed that digital ulcers are associated with osteitis and highlighted calcinosis as another associated factor for osteitis.

Our work highlighted the importance of microbiological documentation in osteitis diagnosis and management. In osteitis, the contribution of bone biopsy in the patient's diagnosis is unequivocal (23). Nevertheless, due to the underlying microangiopathy in SSc, physicians are often reluctant to perform surgical microbiological sampling in SSc patients. Our work demonstrated that both superficial sampling and bone biopsy can be performed safely in SSc patients and led to microbiological identification in 37 cases $(77.1 \%$ of the entire cohort). Imaging is often proposed as an alternative to perform bone biopsy $(24,25)$. As reported by Giuggioli et al., MRI, CT scan and X-rays studies are already used in daily practice for the diagnosis of osteomyelitis, mostly in the context of diabetes (26-30). The SCLEROS study confirms that such examination can identify swelling or abscess of soft tissues with acro-osteolysis or localized collection and soft tissues swelling w/o acro-osteolysis to confirm osteitis in SSc patients. Still, microbiological sampling remains necessary for the management of osteitis as acro-osteolysis or bone inflammation due to calcinosis can be found without infection in SSc patients. As for any other infections, identification of the pathogens is relevant to avoid over-treatment of patients and to reduce the acquired antibiotic resistance (31). In the SCLEROS study, the identification of pathogens allowed to reduce the antibiotics' spectrum and to shorten the mean duration of antibiotherapy ( 34 days vs. 6 weeks in patients with sterile samples). In this series, Staphylococcus aureus; anaerobes and Enterobacteriaceae, and Pseudomonas aeruginosa were the most common pathogens. This is consistent with the work of Giuggioli and Bader who reported in 2008 a frequent association with Gram positive bacteria in diabetic foot infection, another infection of distal limb enhanced by 
microangiopathy $(18,32)$. Still, the presence of $29 \%$ of bacterial floral culture was unexpected and could hypothetically be linked to specific microbiota, inefficient hand washing or multiple use of antibiotic in SSc patients.

Treating osteitis is challenging as the objectives of its management are to decrease the infection, to reconstruct bone structure and surrounding soft tissue, to preserve the affected joints and from the patient's point-of-view, to return to a normal life as quickly as possible with the minimum functional impairment (23). The SCLEROS study showed that treating osteitis in SSc patients is also extremely challenging. Although most patients had a favourable outcome, it showed that 31.3\% SSc patients with osteitis had functional sequelae. Two patients died. Interestingly, the SCLEROS study suggested that after performing microbiological sampling, probabilistic antibiotic with fluoroquinolone or amoxicillin and beta-lactamase inhibitor may be relevant. As it is efficient on staphylococcus spp, streptococcus spp, enterobacteria and pyocyanic, such antibiotherapy is already recommended in diabetic foot infections (33). In the SCLEROS study, patients with microbiological identification had pathogens for which such antibiotherapy was or would have been efficient. Moreover, 6 patients without microbiological identification were managed with such probabilistic antibiotherapy and had a favourable outcome.

The SCLEROS study has some limitations. First, considering the methodology of the call (i.e. a retrospective study), a memory bias could be present. Involved investigators may have reported difficult or severe clinical situations. This possible selection of severe cases might be an explanation for the notified death and sequelae. Moreover, patients with osteitis lacking any clinical symptoms might have been missed in this call. Indeed, some patients with osteomyelitis can be diagnosed with osteitis only on the basis of CT scan or MRI results. Second, due to the retrospective methodology also, radiological examinations were not reanalyzed by a centralized radiologist for the purpose of the study and a prospective study on radiological examination in SSc osteitis should be performed. Third, possible differences regarding the modalities of local care and surgical cleansing may have an impact on osteitis recovery results. Nevertheless, it is difficult to standardize these treatments as they depend on the local presentation of osteitis and physician's practices. Last, no assessment of the disability and the quality of life due to osteitis in SSc was performed. Therefore, we were not able to describe the functional consequences of osteitis in SSc. Despite these weaknesses, this call is the first study describing osteitis in patients with SSc. Moreover, as this study was not tailored for prevalence's calculation, the chosen design was 
appropriate to answer the research question i.e. the description of osteitis in SSc patients. Besides, the data presented in SCLEROS reflected daily practice and stood for a homogeneous cohort of osteitis.

\section{CONCLUSION}

This study characterized osteitis in SSc patients. It confirmed digital tip ulcers as an associated factor for osteitis and revealed a high rate of functional sequelae. It showed that antimicrobial bitherapy with either oral fluoroquinolone or intravenous amoxicillin and beta-lactamase inhibitor are used as first-line antibiotherapy in SSc patients with osteitis.

\section{ACKOWLEDGMENT}

The authors thank the members of the Groupe Francophone de Recherche sur la Sclérodermie, the Société Nationale Française de Médecine Interne, the Société de Pathologie Infectieuse de Langue Française and the Club Rhumatismes et Inflammations for their participation in the study.

\section{REFERENCES}

1. Cutolo M, Soldano S, Smith V. Pathophysiology of systemic sclerosis: current understanding and new insights. Expert Rev Clin Immunol. 2019;15(7):753-64.

2. Dumoitier N, Lofek S, Mouthon L. Pathophysiology of systemic sclerosis: state of the art in 2014. Presse Med. 2014;43(10 Pt 2):e267-78.

3. Denton CP, Khanna D. Systemic sclerosis. Lancet. 2017;390(10103):1685-99.

4. Botou A, Bangeas A, Alexiou I, Sakkas LI. Acro-osteolysis. Clin Rheumatol. 2017;36(1):9-14.

5. Sakkas LI, Bogdanos DP. Infections as a cause of autoimmune rheumatic diseases. Auto Immun Highlights. 2016;7(1):13.

6. Sharp CA, Akram Q, Hughes M, Muir L, Herrick AL. Differential diagnosis of critical digital ischemia in systemic sclerosis: Report of five cases and review of the literature. Semin Arthritis Rheum. 2016;46(2):209-16. 
7. Becker M, Graf N, Sauter R, Allanore Y, Curram J, Denton CP, et al. Predictors of disease worsening defined by progression of organ damage in diffuse systemic sclerosis: a European Scleroderma Trials and Research (EUSTAR) analysis. Ann Rheum Dis. 2019;78(9):1242-8.

8. Ea HZ, V. Lhotellier, L. Ziza, J.M. Mamoudy, P; Desplaces N. Chronic osteitis in adults: diagnosis and treatment. Antibiotiques. 2007;9(22):120.

9. Norden CB, A. Treatment of experimental chronic osteomyelitis due to Staphylococcus aureus with ampicillin/sulbactam. J Infect Dis. 1990;161:52.

10. Allanore Y, Denton CP, Krieg T, Cornelisse P, Rosenberg D, Schwierin B, et al. Clinical characteristics and predictors of gangrene in patients with systemic sclerosis and digital ulcers in the Digital Ulcer Outcome Registry: a prospective, observational cohort. Ann Rheum Dis. 2016;75(9):1736-40.

11. van den Hoogen F, Khanna D, Fransen J, Johnson SR, Baron M, Tyndall A, et al. 2013 classification criteria for systemic sclerosis: an American College of Rheumatology/European League against Rheumatism collaborative initiative. Arthritis Rheum. 2013;65(11):2737-47.

12. Mader JT, Mohan D, Calhoun J. A practical guide to the diagnosis and management of bone and joint infections. Drugs. 1997;54(2):253-64.

13. Berendt AR, Peters EJ, Bakker K, Embil JM, Eneroth M, Hinchliffe RJ, et al. Diabetic foot osteomyelitis: a progress report on diagnosis and a systematic review of treatment. Diabetes Metab Res Rev. 2008;24 Suppl 1:S145-61.

14. Hamajima N, Hirose K, Inoue M, Takezaki T, Kuroishi T, Tajima K. Case-control studies: matched controls or all available controls? J Clin Epidemiol. 1994;47(9):971-5.

15. Groenwold RHH, van Smeden M. Efficient Sampling in Unmatched Case-Control Studies When the Total Number of Cases and Controls Is Fixed. Epidemiology. 2017;28(6):834-7.

16. LeRoy EC, Black C, Fleischmajer R, Jablonska S, Krieg T, Medsger TA, Jr., et al. Scleroderma (systemic sclerosis): classification, subsets and pathogenesis. J Rheumatol. 1988;15(2):202-5.

17. von Elm E, Altman DG, Egger M, Pocock SJ, Gotzsche PC, Vandenbroucke JP, et al. The Strengthening the Reporting of Observational Studies in Epidemiology (STROBE) Statement: guidelines for reporting observational studies. Int J Surg. 2014;12(12):1495-9.

18. Giuggioli D, Manfredi A, Colaci M, Lumetti F, Ferri C. Osteomyelitis complicating scleroderma digital ulcers. Clin Rheumatol. 2013;32(5):623-7. 
19. Mihai C, Landewe R, van der Heijde D, Walker UA, Constantin PI, Gherghe AM, et al. Digital ulcers predict a worse disease course in patients with systemic sclerosis. Ann Rheum Dis. 2016;75(4):681-6.

20. Hachulla E, Clerson P, Launay D, Lambert M, Morell-Dubois S, Queyrel V, et al. Natural history of ischemic digital ulcers in systemic sclerosis: single-center retrospective longitudinal study. J Rheumatol. 2007;34(12):2423-30.

21. Bogoch ER, Gross DK. Surgery of the hand in patients with systemic sclerosis: outcomes and considerations. J Rheumatol. 2005;32(4):642-8.

22. Blagojevic J, Abignano G, Avouac J, Cometi L, Frerix M, Bellando-Randone S, et al. Use of vasoactive/vasodilating drugs for systemic sclerosis (SSc)-related digital ulcers (DUs) in expert tertiary centres: results from the analysis of the observational real-life DeSScipher study. Clin Rheumatol. 2019.

23. Tiemann AH, Hofmann GO, Steen M, Schmidt R. Adult calcaneal osteitis: incidence, etiology, diagnostics and therapy. GMS Interdiscip Plast Reconstr Surg DGPW. 2012;1:Doc11.

24. Zhou AY, Muir L, Harris J, Herrick AL. The impact of magnetic resonance imaging in early diagnosis of hand osteomyelitis in patients with systemic sclerosis. Clin Exp Rheumatol. 2014;32(6 Suppl 86):S-232.

25. McQueen FM. Bone marrow edema and osteitis in rheumatoid arthritis: the imaging perspective. Arthritis Res Ther. 2012;14(5):224.

26. Lauri C, Tamminga M, Glaudemans A, Juarez Orozco LE, Erba PA, Jutte PC, et al. Detection of Osteomyelitis in the Diabetic Foot by Imaging Techniques: A Systematic Review and Meta-analysis Comparing MRI, White Blood Cell Scintigraphy, and FDG-PET. Diabetes Care. 2017;40(8):1111-20.

27. Dinh T, Snyder G, Veves A. Current techniques to detect foot infection in the diabetic patient. Int J Low Extrem Wounds. 2010;9(1):24-30.

28. Lew DP, Waldvogel FA. Osteomyelitis. Lancet. 2004;364(9431):369-79.

29. Romano CL, Romano D, Logoluso N, Drago L. Bone and joint infections in adults: a comprehensive classification proposal. Eur Orthop Traumatol. 2011;1(6):207-17.

30. Gentry LO. Management of osteomyelitis. Int J Antimicrob Agents. 1997;9(1):37-42.

31. Maleb A, Frikh M, Lahlou YB, Chagar B, Lemnouer A, Elouennass M. Bacteriological aspects of chronic osteoarticular infections in adults: the influence of the osteosynthesis material. BMC Res Notes. 2017;10(1):635. 
32. Bader MS. Diabetic foot infection. Am Fam Physician. 2008;78(1):71-9.

33. Diamantopoulos EJ, Haritos D, Yfandi G, Grigoriadou M, Margariti G, Paniara O, et al.

Management and outcome of severe diabetic foot infections. Exp Clin Endocrinol Diabetes. $1998 ; 106(4): 346-52$. 


\section{TABLES}

Table 1. Patients' baseline characteristics

Table 2. Osteitis characteristics in SSc patients

Table 3. Management and prognosis of osteitis in SSc patients

Table 4. Antibiotics management in SSc osteitis

Table 5. Associated factors for osteitis in SSc patients

Supplemental Table 1. Detailed scheme of antibiotherapy regimen

Supplemental Table 2. Associated factors for osteitis overlying digital ulcer

Supplemental Table 3. Associated factors of osteitis' healing for the entire cohort 
Table 1. Patients' baseline characteristics

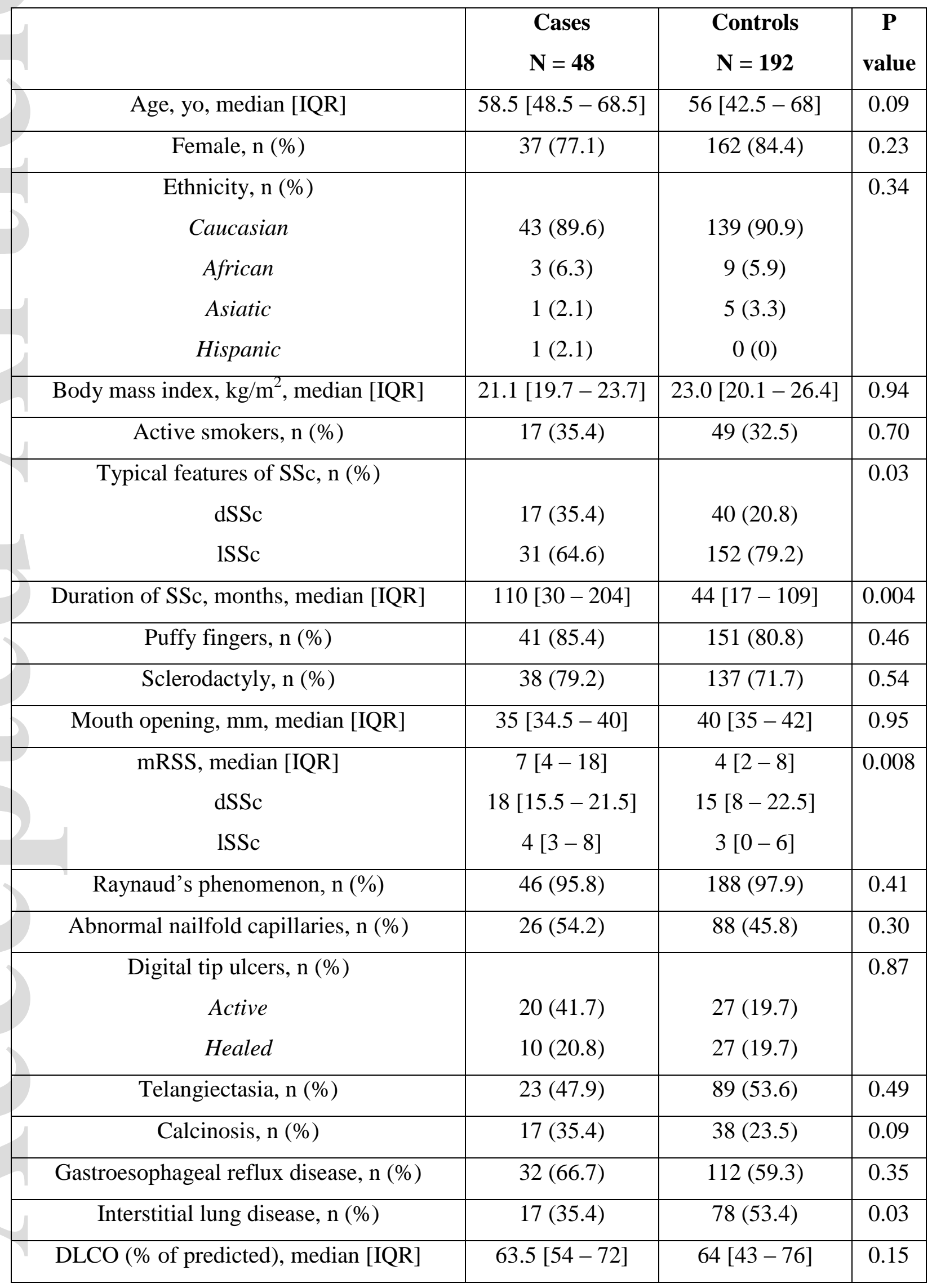




\begin{tabular}{|c|c|c|c|}
\hline FVC (\% of predicted), median [IQR] & $90.5[82-102]$ & $91[74-112]$ & 0.66 \\
\hline Pulmonary arterial hypertension, n (\%) & $4(8.3)$ & $22(15.3)$ & 0.22 \\
\hline PAPs, mmHg, median [IQR] & $33[30-39]$ & $31.5[27-37]$ & 0.30 \\
\hline Musculoskeletal disorders, n (\%) & $19(39.6)$ & $60(32.6)$ & 0.36 \\
\hline Scleroderma renal crisis, n (\%) & $4(8.3)$ & $22(15.3)$ & 0.22 \\
\hline Autoantibodies, n (\% positive in patients & & & \\
tested) & $25(52.1)$ & $73(38.0)$ & 0.08 \\
Anti-centromere & $11(22.9)$ & $46(23.9)$ & 0.88 \\
Anti-topoisomerase I & $3(6.3)$ & $6(3.1)$ & 0.31 \\
Anti-RNA polymerase III & $12(25.0)$ & $54(28.1)$ & 0.67 \\
\hline Immunosuppressant, n (\%) & $18(37.5)$ & $68(47.6)$ & 0.23 \\
\hline Corticosteroids, n (\%) & & & \\
\hline
\end{tabular}

DLCO: diffusing capacity of the lung for carbon monoxide; dSSc: diffuse systemic sclerosis; FVC: forced vital capacity; IQR: interquartile range; ISSc: limited systemic sclerosis; $m R S S$ : modified Rodnan skin score; PAPs: systolic pulmonary arterial pressure; SSc: systemic sclerosis 
Table 2. Osteitis characteristics in SSc patients

\begin{tabular}{|c|c|c|c|}
\hline & $\begin{array}{c}\text { SCLEROS } \\
\text { cases } \\
\mathbf{N}=\mathbf{4 8}\end{array}$ & $\begin{array}{c}\text { Patients with } \\
\text { osteitis overlying } \\
\text { digital tip ulcers } \\
\qquad \mathrm{N}=\mathbf{2 6}\end{array}$ & $\begin{array}{c}\text { Patients with } \\
\text { osteitis w/o digital } \\
\text { tip ulcers } \\
\mathrm{N}=\mathbf{2 2}\end{array}$ \\
\hline \multicolumn{4}{|c|}{ Clinical manifestations } \\
\hline $\begin{array}{c}\text { Time from systemic sclerosis diagnosis, } \\
\text { months, median [IQR] }\end{array}$ & $113(27-201)$ & $90(6-120)$ & $144(42-240)$ \\
\hline$d S S c$ & $48(24-120)$ & $96(26-131)$ & $45(28.5-48)$ \\
\hline$l S S c$ & $121(63-210)$ & $108(48-120)$ & $144(122-240)$ \\
\hline \multicolumn{4}{|l|}{ Osteitis location, $\mathrm{n}(\%)$} \\
\hline Toe $(R / L)$ & $19(39.6)$ & $7(26.9)$ & $12(54.6)$ \\
\hline $\operatorname{Hand}(R / L)$ & $25(52.1)$ & $18(69.2)$ & $7(31.8)$ \\
\hline $\operatorname{Elbow}(R / L)$ & $2(4.2)$ & $1(3.9)$ & $1(4.6)$ \\
\hline Other location: femur / sternum & $1(2.1) / 1(2.1)$ & $0(0) / 0(0)$ & $1(2.1) / 1(2.1)$ \\
\hline Overlying calcinosis, $\mathrm{n}(\%)$ & $13(27.1)$ & $8(30.8)$ & $5(22.7)$ \\
\hline $\begin{array}{l}\text { Duration of osteitis, months, median } \\
\text { [IQR] }\end{array}$ & $3(1-6)$ & $3(1-8)$ & $2.5(1-4)$ \\
\hline Fever $\left(\mathrm{T}>37.8^{\circ} \mathrm{C}\right), \mathrm{n}(\%)$ & $4(8.3)$ & $2(7.7)$ & $2(9.1)$ \\
\hline Local pain, n (\%) & $36(75)$ & $22(84.6)$ & $14(63.6)$ \\
\hline Functional disability, n (\%) & $29(60.4)$ & $17(65.4)$ & $12(54.6)$ \\
\hline Purulent discharge, n (\%) & $27(56.3)$ & $15(57.7)$ & $12(54.6)$ \\
\hline Local swelling, n (\%) & $26(54.2)$ & $19(73.1)$ & $7(31.8)$ \\
\hline Erythema, n (\%) & $35(72.9)$ & $22(84.6)$ & $13(59.1)$ \\
\hline Local warmth, n (\%) & $35(72.9)$ & $20(76.9)$ & $15(68.2)$ \\
\hline \multicolumn{4}{|c|}{ Biological manifestations } \\
\hline C-reactive protein, $\mathrm{mg} / \mathrm{L}$, median $[\mathrm{IQR}]$ & $8(2.7-44.3)$ & $7.2(2.7-37.5)$ & $12(2.7-60.0)$ \\
\hline Increased CRP value, $\mathrm{n}(\%)$ & $31(65.9)$ & $15(60.0)$ & $16(72.7)$ \\
\hline Hyperleukocytosis $\left(>8000 / \mathrm{mm}^{3}\right), \mathrm{n}(\%)$ & $13(27.1)$ & $8(30.8)$ & $5(22.7)$ \\
\hline Leukocytes, $/ \mathrm{mm}^{3}$, median [IQR] & $7300(5000-8890)$ & $7400(5435-9820)$ & $\begin{array}{c}6385(4390- \\
7900)\end{array}$ \\
\hline Haemoglobin, g/dL, median [IQR] & $11.8(10.6-12.8)$ & $12.3(11.1-12.9)$ & $11.4(10.6-12.5)$ \\
\hline
\end{tabular}




\begin{tabular}{|c|c|c|c|}
\hline Platelets, $10^{3} / \mathrm{L}$, median [IQR] & $285(218-341)$ & $284.5(215-341)$ & $288(219-310)$ \\
\hline \multicolumn{4}{|c|}{ Imaging manifestations } \\
\hline Localized collection, $\mathrm{n}(\%)$ & $3(6.3)$ & $0(0)$ & $3(13.6)$ \\
\hline Bone hypermetabolism, n (\%) & $3(6.3)$ & $0(0)$ & $3(13.6)$ \\
\hline Acro-osteolysis or lysis, n (\%) & $23(47.9)$ & $10(38.5)$ & $13(59.1)$ \\
\hline $\begin{array}{l}\text { Swelling or abscess of soft tissues on } \\
\text { MRI or standard X-ray, n (\%) } \\
\text { With acro-osteolysis } \\
\text { W/o acro-osteolysis }\end{array}$ & $\begin{array}{l}28(58.3) \\
3(6.3)\end{array}$ & $\begin{array}{c}14(53.8) \\
2(7.8)\end{array}$ & $\begin{array}{l}14(63.6) \\
1(4.5)\end{array}$ \\
\hline \multicolumn{4}{|c|}{ Sampling } \\
\hline $\begin{array}{l}\text { Peroperative contributive superficial or } \\
\text { needle-guided sampling, n (\% of } \\
\text { performed examination) }\end{array}$ & $14 / 18(77.8)$ & $8 / 10(80.0)$ & $6 / 8(75.0)$ \\
\hline $\begin{array}{c}\text { Contributive deep or surgical sampling, } \\
\text { n (\% of performed examination) }\end{array}$ & $24 / 27(88.9)$ & $14 / 15(93.3)$ & $10 / 12(83.3)$ \\
\hline \multicolumn{4}{|c|}{ Microbiological documentation } \\
\hline Staphylococcus aureus, n (\%) & $21(43.8)$ & $15(57.7)$ & $6(27.3)$ \\
\hline $\begin{array}{c}\text { Coagulase-negative Staphylococcus, } \mathrm{n} \\
(\%)\end{array}$ & $4(8.3)$ & $3(11.5)$ & $1(4.5)$ \\
\hline Enterobacteriaceae, n (\%) & $14(29.1)$ & $8(30.8)$ & $6(27.3)$ \\
\hline Anaerobes, n (\%) & $14(29.1)$ & $7(26.9)$ & $7(31.8)$ \\
\hline Pseudomonas aeruginosa, n (\%) & $5(10.4)$ & $1(3.8)$ & $4(18.2)$ \\
\hline Streptococcus spp, n (\%) & $4(8.3)$ & $4(15.4)$ & $0(0)$ \\
\hline Negative culture, $\mathrm{n}(\%)^{* *}$ & $3(6.5)$ & $1(3.8)$ & $2(9.1)$ \\
\hline
\end{tabular}

CRP: C reactive protein; $d S S c$ : diffuse systemic sclerosis; IQR: interquartile range; $l S S c$ : limited systemic sclerosis; SSc: systemic sclerosis

*: contributive exams correspond to exams in which imaging aspects of osteitis were reported.

**: sterile samples were reported on all SCLEROS population $(\mathrm{n}=48)$ 
Table 3. Management and prognosis of osteitis in SSc patients

\begin{tabular}{|c|c|c|c|}
\hline & $\begin{array}{c}\text { SCLEROS } \\
\text { cases } \\
\mathrm{N}=48\end{array}$ & $\begin{array}{l}\text { Patients with } \\
\text { osteitis overlying } \\
\text { digital tip ulcers } \\
\qquad \mathrm{N}=26\end{array}$ & $\begin{array}{c}\text { Patients with } \\
\text { osteitis w/o } \\
\text { digital tip } \\
\text { ulcers } \\
\text { N }=22\end{array}$ \\
\hline \multicolumn{4}{|c|}{ Management of osteitis } \\
\hline Multidisciplinary management, n (\%) & $24(50.0)$ & $11(42.3)$ & $13(59.1)$ \\
\hline Surgical treatment, n (\%) & $26(54.2)$ & $16(61.5)$ & $10(45.5)$ \\
\hline Antibiotics, n (\%) & $37(77.1)$ & $21(80.8)$ & $16(72.7)$ \\
\hline Local dressing, n (\%) & $35(72.9)$ & $21(80.8)$ & $14(63.6)$ \\
\hline Surgical joints cleansing, $\mathrm{n}(\%)$ & $8(16.7)$ & $4(15.4)$ & $4(18.2)$ \\
\hline Opiates, n (\%) & $10(20.8)$ & $7(26.9)$ & $3(13.6)$ \\
\hline Amputation, $\mathrm{n}(\%)$ & $11(22.9)$ & $8(30.8)$ & $3(13.6)$ \\
\hline Synovectomy, n (\%) & $2(4.2)$ & $1(3.9)$ & $1(4.6)$ \\
\hline \multicolumn{4}{|c|}{ Re-evaluation } \\
\hline Follow-up, months, median [IQR] & $5[2-18]$ & $3.8[2-12]$ & $8[2.5-24]$ \\
\hline Clinical cure, n (\%) & $35(72.9)$ & $19(73.1)$ & $16(72.7)$ \\
\hline $\begin{array}{c}\text { Relapse, } \mathrm{n}(\%) \\
\text { Number of relapse per patient } \\
\text { Homolateral relapse } \\
\text { Time between } 2 \text { episodes, months, median [IQR] }\end{array}$ & $\begin{array}{c}6(12.6) \\
1(0-1) \\
4 / 6 \\
2[1-4]\end{array}$ & $\begin{array}{c}4(15.4) \\
1(0-1) \\
3 / 4 \\
2[1-4]\end{array}$ & $\begin{array}{c}2(9.1) \\
1(0-1) \\
1 / 2 \\
3[2.5-6]\end{array}$ \\
\hline $\begin{array}{l}\text { New episode of osteitis, } \mathrm{n}(\%) \\
\text { Time to the } 2 \text { nd episode, months, median [IQR] }\end{array}$ & $\begin{array}{l}8(16.6) \\
6(5-9)\end{array}$ & $\begin{array}{c}7(26.9) \\
5(3-10)\end{array}$ & $\begin{array}{c}1(4.5) \\
6(5-7)\end{array}$ \\
\hline Sequelae, n (\%) & $15(31.3)$ & $10(38.5)$ & $5(22.7)$ \\
\hline Death related to osteitis, n (\%) & $2(4.2)$ & $2(7.7)$ & $0(0)$ \\
\hline
\end{tabular}

DU: digital ulcer; [IQR]: interquartile range; w/o: without 
Table 4. Antibiotics management in SSc osteitis

\begin{tabular}{|c|c|c|c|c|c|c|}
\hline & & & & \multicolumn{3}{|c|}{$\begin{array}{l}\text { SCLEROS cases } \\
\qquad \mathbf{N}=\mathbf{4 8}\end{array}$} \\
\hline \multicolumn{7}{|c|}{ Characteristics of antibiotherapy } \\
\hline \multicolumn{4}{|c|}{ Duration of treatment, days, median [IQR] } & \multicolumn{3}{|c|}{$41[5.5-55]$} \\
\hline \multicolumn{4}{|c|}{ Bitherapy, n (\%) } & \multicolumn{3}{|c|}{$\begin{array}{c}23(4 / .9) \\
41[30-49]\end{array}$} \\
\hline \multicolumn{4}{|c|}{ Duration of Intravenous administration, days, median [IQR] } & \multicolumn{3}{|c|}{$9[0-56]$} \\
\hline \multicolumn{4}{|c|}{ Duration of orally administration, days, median [IQR] } & \multicolumn{3}{|c|}{$29[0-51.5]$} \\
\hline \multicolumn{4}{|c|}{ Duration of switch from IVD to orally, days, median [IQR] } & \multicolumn{3}{|c|}{$1[0-40]$} \\
\hline \multicolumn{7}{|c|}{ Main antibiotics regimens } \\
\hline & & Antibiotics & Count & $\begin{array}{l}\text { Duration, days, } \\
\text { median }[\mathrm{IQR}]\end{array}$ & $\begin{array}{l}\text { Orally / IVDD } \\
\text { administration }\end{array}$ & $\begin{array}{l}\text { Monotherapy } \\
\text { / bitherapy }\end{array}$ \\
\hline \multirow{3}{*}{$1^{\text {st }}$ line } & $1^{\mathrm{st}}$ & Fluoroquinolone & $19 / 48$ & $34[10-50]$ & $15 / 4$ & $4 / 15$ \\
\hline & $2^{\text {nd }}$ & $\begin{array}{c}\text { Amoxicillin +/- } \\
\text { Beta lactamase } \\
\text { inhibitor }\end{array}$ & $15 / 48$ & $30[12-42]$ & $14 / 1$ & $4 / 11$ \\
\hline & $3^{\text {rd }}$ & Macrolides & $7 / 48$ & $35[15-42]$ & $7 / 0$ & $1 / 6$ \\
\hline \multirow{3}{*}{$2^{\text {nd }}$ line } & $1^{\mathrm{st}}$ & Fluoroquinolone & $10 / 48$ & $32[27-42]$ & $8 / 2$ & $2 / 8$ \\
\hline & $2^{\text {nd }}$ & Rifampicin & $4 / 48$ & $42[35-67]$ & $3 / 1$ & $0 / 4$ \\
\hline & $3^{\text {rd }}$ & $\begin{array}{l}\text { Penicillin }+/- \\
\text { inhibitor }\end{array}$ & $3 / 48$ & $5[3-17]$ & $1 / 2$ & $3 / 0$ \\
\hline
\end{tabular}

* these 2 patients received rifampicin for 40 days

[IQR]: interquartile range; IVD: intravenous; w/o: without 
Table 5. Factors associated with osteitis in SSc patients

\begin{tabular}{|c|c|c|c|c|}
\hline & \multicolumn{2}{|c|}{ Univariate analysis } & \multicolumn{2}{|c|}{ Multivariable analysis } \\
\hline & OR $(95 \% \mathrm{Cl})$ & Pvalue & OR $(95 \% \mathrm{Cl})$ & Pvalue \\
\hline Age & $1.01(0.99-1.03)$ & 0.19 & / & / \\
\hline Female sex & $0.62(0.29-1.36)$ & 0.23 & / & / \\
\hline Body mass index & $0.94(0.88-1.02)$ & 0.12 & $0.96(0.87-1.07)$ & 0.51 \\
\hline Active smoking & $1.14(0.58-2.26)$ & 0.70 & / & / \\
\hline ISSC & $0.48(0.24-0.95)$ & 0.04 & $0.76(0.17-3.35)$ & 0.72 \\
\hline Duration of SSc & $1.01(1.01-1.02)$ & 0.02 & $1.01(0.99-1.01)$ & 0.44 \\
\hline Puffy fingers & $1.39(0.58-3.37)$ & 0.46 & / & / \\
\hline Sclerodactyly & $1.53(0.71-3.27)$ & 0.28 & / & / \\
\hline $\mathrm{mRSS}$ & $1.05(1.01-1.09)$ & 0.02 & $1.02(0.94-1.10)$ & 0.65 \\
\hline Raynaud's phenomenon & $0.49(0.09-2.75)$ & 0.42 & / & / \\
\hline Abnormal nailfold capillaries & $0.79(0.09-3.19)$ & 0.74 & / & / \\
\hline Digital tip ulcers & $2.29(1.18-4.45)$ & 0.01 & $4.26(1.43-12.66)$ & 0.009 \\
\hline Telangiectasia & $0.79(0.41-1.51)$ & 0.49 & / & / \\
\hline Calcinosis & $1.49(0.89-3.59)$ & 0.10 & $3.13(1.16-8.47)$ & 0.03 \\
\hline Gastroesophageal reflux disease & $1.38(0.71-2.68)$ & 0.35 & / & / \\
\hline Interstitial lung disease & $0.48(0.24-0.94)$ & 0.03 & $0.62(0.22-1.73)$ & 0.36 \\
\hline
\end{tabular}




\begin{tabular}{|c|c|c|c|c|}
\hline Pulmonary arterial hypertension & $0.50(0.16-1.54)$ & 0.23 & / & / \\
\hline Musculo-skeletal disorders & $1.35(0.70-2.61)$ & 0.37 & / & / \\
\hline Scleroderma renal crisis & $0.55(0.18-1.69)$ & 0.29 & / & / \\
\hline Anti-centromere autoantibodies & $1.26(0.98-2.17)$ & 0.08 & $1.17(0.85-3.01)$ & 0.41 \\
\hline Anti-topoisomerase I autoantibodies & $0.98(0.62-1.26)$ & 0.31 & / & / \\
\hline Anti-RNA polymerase III autoantibodies & $0.83(0.22-1.39)$ & 0.55 & / & / \\
\hline Immunosuppressant w/o CTC & $4.20(0.82-2.50)$ & 0.09 & $2.86(0.27-30.74)$ & 0.39 \\
\hline Corticosteroids & $0.66(0.34-1.29)$ & 0.23 & / & / \\
\hline
\end{tabular}

CTC: corticosteroids; ISSc: limited systemic sclerosis; mRSS: modified Rodnan skin score; SSc: systemic sclerosis 